\title{
Mentoring experience and its effects on medical interns
}

\author{
Eui-Ryoung $\underline{\operatorname{Han}}^{1}, \mathrm{MD}$, Eun-Kyung Chung${ }^{2}$, MD, Sun-A $\underline{\mathrm{Oh}}^{3}$, $\mathrm{PhD}$, Young-Jong $\underline{\text { Woo }}^{2}$, MD, Maurice A Hitchcock${ }^{4}$, MD
}

INTRODUCTION Effective mentoring helps interns in the early stages of their medical career to reach personal and professional goals. This study investigated the mentoring experience of Korean interns during medical internship and evaluated mentoring effects to facilitate the development of future mentoring programmes.

METHODS Participants were interns being trained at Chonnam National University Hospital, South Korea, in 2011. Interns were asked to complete a questionnaire about their mentoring experiences and job satisfaction.

RESULTS A total of 61 medical interns participated in the study, giving a response rate of $70.1 \%$. Among these interns, $26(42.6 \%)$ had mentoring experiences, with an average of $2.3 \pm 1.9$ mentors per mentee. Mentees usually discussed career planning and concerns regarding their personal and social lives with their mentors. Perceived quality of the mentor was significantly more important for male mentees than for female mentees. Female interns without a mentor made significantly less effort to seek a mentor than their male counterparts. Having and not having a mentor resulted in significant differences in the interns' job satisfaction.

CONCLUSION Fewer than half of the medical interns had mentoring experiences. Results suggest that the mentoring relationship may be less satisfying and more challenging for female interns. Effective mentoring may not only help interns plan their medical career, but also increase job satisfaction. Mentoring programmes during medical internship should be expanded and supported, as it is the initial step in a medical career.

Keywords: career counselling, internship, job satisfaction, mentorships

\section{INTRODUCTION}

Mentoring is defined as a process whereby an experienced, highly regarded, empathetic person (i.e. the mentor) guides another individual (i.e. the mentee) in the development and re-examination of the latter's ideas, learning, and personal and professional development. ${ }^{(1)} \mathrm{A}$ mentor is an active partner in the ongoing relationship between mentor and mentee, helping the mentee maximise his or her potential, and reach personal and professional goals. ${ }^{(2,3)}$

In some countries, medical graduates must complete a rotating internship followed by a residency programme in their area of specialty in order to become a medical specialist. Interns taking their first step to becoming independent professionals may wonder who to choose as role models, often demonstrating enthusiasm, passion and support for the specialties they are interested in. ${ }^{(4)}$ Osborn reported that a faculty advisor was the most significant factor affecting the specialty choice of medical school graduates entering residency training in the primary care fields of internal medicine, paediatrics and family medicine. ${ }^{(5)}$

Although interns starting their internship have more vigour than the general adult and college student populations, they progressively exhibit greater fatigue and anger as the internship year progresses. ${ }^{(6)}$ Intense work demands, limited control and work-home interference in training programmes also strongly predispose residents to burnout. ${ }^{(7)}$ Young physicians who readily embrace the hard work are especially prone to experiencing high levels of professional burnout during their training years. ${ }^{(7)}$ As a result, many medical interns have been leaving teaching hospitals each year due to burnout. ${ }^{(8)}$ While most of these interns move to other hospitals, a few have even left the training programme altogether. ${ }^{(8)}$

Research on mentoring in Western countries reported that effective mentoring resulted in reduced burnout and increased physician retention. ${ }^{(9)}$ Notably, mentoring during the early stages of a career was found to help mentees enjoy greater career satisfaction. ${ }^{(10)}$ However, few studies have examined the mentoring experiences of physicians in Asian countries, ${ }^{(11)}$ where cultural differences in vertical relationships are evident, compared to Western countries. ${ }^{(12)}$ Given the paucity of such research, we investigated the mentoring experiences of Korean interns in the absence of a formal mentoring programme and assessed how they perceived their mentors. Additionally, we compared job satisfaction between interns with mentors and those without. We believe that the results of this study will aid and facilitate the development of future mentoring programmes for interns.

\section{METHODS}

Medical interns were recruited from Chonnam National University Hospital, South Korea, in November 2011. The interns had been trained at each clinical department in rotation for one year before they chose a specialisation. A total of 87 interns were scheduled to be in training from March to February the following year. The institutional review board determined that the study was exempt from human subject research regulations. Participation in the survey was voluntary and students were informed that their responses would remain confidential. Written consent was obtained from all participants.

${ }^{1}$ Office of Education and Research, Chonnam National University Hospital, ${ }^{2}$ Department of Medical Education, Chonnam National University Medical School, ${ }^{3} \mathrm{Center}$ for Teaching and Learning, Gwangju University, Gwangju, South Korea, ${ }^{4}$ Division of Medical Education, Keck School of Medicine of the University of Southern California, Los Angeles, USA Correspondence: Dr Eun-Kyung Chung, Associate Professor, Department of Medical Education, Chonnam National University Medical School, 160 Baekseo-ro, Dong-gu, Gwangju, 501-746, South Korea. ekcmedu@chonnam.ac.kr 
The participants completed an anonymous questionnaire about their mentoring experience, perceived quality of the mentor and job satisfaction. In the present study, the mentor was defined as 'someone with whom you have had a longitudinal professional relationship; someone who has more knowledge or experience than you have; someone to whom you turn for advice and support; and someone who is committed to your personal and professional development'. Questions about the mentoring experience allowed multiple responses. Respondents were asked to provide the general characteristics and qualities of their mentor. Respondents who had two or more mentors answered the questions with reference to the chief mentor, i.e. the mentor who had the greatest effect on them. Perceived quality of the mentor was measured using the Mentorship Effectiveness Scale, ${ }^{(13)}$ and its 12 items were assessed using a six-point Likert scale, as follows: $0=$ strongly disagree; 1 = disagree; 2 = slightly disagree; 3 = slightly agree; 4 = agree; and $5=$ strongly agree. For the 12 items of the Mentorship Effectiveness Scale, ${ }^{(13)}$ Cronbach's alpha was 0.931 , with a $95 \%$ confidence interval $(\mathrm{Cl})$ of 0.882-0.966. Respondents who had never had a mentor answered questions using a five-point Likert scale regarding the effort they made in seeking a mentor. In addition, the reasons why these interns did not have a mentor were assessed using multiple-coded questions.

Job satisfaction was an indication of the employees' overall state of satisfaction. The short, 20-item version of the Minnesota Satisfaction Questionnaire, ${ }^{(14)}$ a well-constructed scale for measuring work satisfaction in the mentoring programme, ${ }^{(15)}$ was used in this study. The questions were answered on a five-point Likert scale, as follows: 1 = very dissatisfied; 2 = dissatisfied; $3=$ neither satisfied nor dissatisfied; 4 = satisfied; and $5=$ very satisfied. For the 20 items on this scale, Cronbach's alpha was 0.941 (95\% Cl 0.917-0.961).

The study participants were divided into two groups - interns who had a mentor, and those who did not. Chi-square test was used to compare general characteristics, while the Mann-Whitney $U$ test was used to determine significant differences in mentoring effects between the two intern groups. All analyses were performed using the Statistical Package for the Social Sciences version 20.0 (SPSS Inc, Chicago, IL, USA).

\section{RESULTS}

Among the 87 scheduled to undergo internship, 61 medical interns participated in the study, giving a response rate of $70.1 \%$. Among the respondents, 26 (42.6\%) interns were mentored. The respondents' characteristics are summarised in Table I. With respect to variables such as gender, age and marital status, there were no significant differences between interns with mentors and those without.

On average in the present study, mentees had $2.3 \pm$ 1.9 mentors. Among the 26 mentees, 94.1\% $(n=16)$ of the male interns and $33.3 \%(n=3)$ of the female interns had a chief mentor of the same gender. The chief mentors included 22 men and 4 women. The documented mentoring experiences with chief mentors are presented in Table II. Most chief mentors were higher in seniority (42.3\%) than their mentees and affiliated with
Table I. General characteristics of interns $(n=61)$, according to mentoring experience.

\begin{tabular}{lccc}
\hline Variable & \multicolumn{2}{c}{ No. of interns (\%) } & p-value \\
\cline { 2 - 3 } & $\begin{array}{c}\text { With mentors } \\
(\mathbf{n}=\mathbf{2 6})\end{array}$ & $\begin{array}{c}\text { Without mentors } \\
(\mathbf{n}=\mathbf{3 5})\end{array}$ & \\
\hline Gender & $17(65.4)$ & $22(62.9)$ & 0.839 \\
Men & $9(34.6)$ & $13(37.1)$ & \\
Women & $26.5 \pm 2.2$ & $26.7 \pm 2.0$ & 0.677 \\
Age* (yr) & $3(11.5)$ & $7(20.0)$ & 0.325 \\
Marital status ${ }^{+}$ & $23(88.5)$ & $26(74.3)$ & \\
Married & & & \\
Single & & & \\
\hline
\end{tabular}

* Data is presented as mean \pm standard deviation. ${ }^{\text {D }}$ Data was not available for two interns without mentors.

Table II. General characteristics of chief mentors $(n=26)$ and mentoring experience.

\begin{tabular}{|c|c|}
\hline Variable & No. (\%) \\
\hline \multicolumn{2}{|l|}{ Gender } \\
\hline Men & $22(84.6)$ \\
\hline Women & $4(15.4)$ \\
\hline \multicolumn{2}{|l|}{ Seniority* } \\
\hline Peer & $6(23.1)$ \\
\hline Senior & $11(42.3)$ \\
\hline Professor & $5(19.2)$ \\
\hline \multicolumn{2}{|l|}{ Affiliation ${ }^{*,+}$} \\
\hline Same hospital & $16(61.5)$ \\
\hline Same medical school & $7(26.9)$ \\
\hline Different hospital & $3(11.5)$ \\
\hline Different medical school & $1(3.8)$ \\
\hline \multicolumn{2}{|l|}{ Frequency of contact } \\
\hline More than once per month & $13(50.0)$ \\
\hline About once every two months & $7(26.9)$ \\
\hline Less than five times a year & $4(15.4)$ \\
\hline \multicolumn{2}{|l|}{ Communication method ${ }^{+}$} \\
\hline Face-to-face meeting & $21(80.8)$ \\
\hline Telephone call & $13(50.0)$ \\
\hline Mail & $1(3.8)$ \\
\hline \multicolumn{2}{|l|}{ Topics discussed $^{+}$} \\
\hline Career planning & $21(80.8)$ \\
\hline Personal life concerns & $19(73.1)$ \\
\hline Social life concerns & $12(46.2)$ \\
\hline Patient management & $5(19.2)$ \\
\hline Presentation of research papers & $2(7.7)$ \\
\hline
\end{tabular}

*With respect to the mentee. + Multiple-coded questions.

the same hospital $(61.5 \%)$ as the mentee. More than half of the chief mentors interacted with the interns frequently, i.e. more than once per month (54.2\%). Mentors and mentees either met face-to-face ( $80.8 \%$ ) or communicated by telephone (50.0\%). The main topic of discussion was career planning (80.8\%).

The highest score was given to 'mentors' support and encouragement' $(4.4 \pm 0.7)$, while the lowest score was accorded to 'suggesting appropriate resources' $(3.7 \pm 0.9)$. With regard to the gender of the mentees, the overall assessment of mentoring was significantly more positive among male mentees than female mentees. This was particularly true for assessments of the professional integrity $(p=0.019)$ and approachability $(p=0.037)$ of the mentor, which were scored much higher by male mentees than female mentees (Table III). However, the perceived quality 
Table III. Perceived quality of the mentor according to mentees' gender.*

\begin{tabular}{|c|c|c|c|}
\hline \multirow[t]{2}{*}{ Variable } & \multicolumn{2}{|c|}{ Mean \pm SD } & \multirow[t]{2}{*}{ p-value } \\
\hline & Men & Women & \\
\hline My mentor was accessible. & $4.4 \pm 0.7$ & $4.0 \pm 0.5$ & 0.095 \\
\hline My mentor demonstrated professional integrity. & $4.5 \pm 0.6$ & $3.9 \pm 0.6$ & $0.019^{+}$ \\
\hline My mentor demonstrated content expertise in my area of need. & $4.1 \pm 0.7$ & $3.3 \pm 1.3$ & 0.110 \\
\hline My mentor was approachable. & $4.6 \pm 0.6$ & $4.0 \pm 0.7$ & $0.037^{+}$ \\
\hline My mentor provided constructive and useful critiques of my work. & $4.3 \pm 0.8$ & $4.0 \pm 0.7$ & 0.310 \\
\hline My mentor motivated me to improve my work product. & $4.4 \pm 0.7$ & $4.0 \pm 0.9$ & 0.221 \\
\hline $\begin{array}{l}\text { My mentor was helpful in providing direction and guidance } \\
\text { regarding professional issues (e.g. networking). }\end{array}$ & $4.5 \pm 0.6$ & $4.0 \pm 0.9$ & 0.159 \\
\hline $\begin{array}{l}\text { My mentor answered my questions satisfactorily (e.g. timely } \\
\text { response, clear, comprehensive). }\end{array}$ & $4.3 \pm 0.8$ & $3.8 \pm 1.0$ & 0.167 \\
\hline $\begin{array}{l}\text { My mentor suggested appropriate resources (e.g. experts, } \\
\text { electronic contacts, source materials). }\end{array}$ & $3.9 \pm 0.9$ & $3.3 \pm 0.9$ & 0.095 \\
\hline $\begin{array}{l}\text { My mentor challenged me to extend my abilities (e.g. risk-taking, } \\
\text { trying a new professional activity), drafting a section of an article). }\end{array}$ & $4.0 \pm 0.8$ & $3.5 \pm 0.8$ & 0.135 \\
\hline Total mentorship effectiveness score & $51.7 \pm 6.4$ & $45.4 \pm 6.8$ & $0.038^{+}$ \\
\hline
\end{tabular}

* Data indicated the effectiveness of the chief mentor, as scored on a six-point Likert scale. ${ }^{\mathrm{t} p}$-value < 0.05 was considered statistically significant. SD: standard deviation

of mentoring did not differ between male and female mentors or between mentors of the same and opposite gender as the mentee (data not shown).

In the present study, interns with mentors reported much greater job satisfaction than those without mentors $(p=0.006)$, especially with respect to the feeling of accomplishment, and the opportunity to be indispensable in the community, to work independently and to try out their own work approaches. We found that mentees responded positively to the question regarding whether they would continue working at the same hospital $(p=0.003$ ) (Table IV). With regard to career choice, such as deciding whether to enter a residency training programme or the type of specialty to apply for, no significant difference between interns with mentors and those without was found (data not shown).

Interns without a mentor $(\mathrm{n}=35)$ had none for the following reasons: (a) a lack of time for mentoring (48.6\%); (b) difficulty in developing a mentoring relationship with their superiors (25.7\%); (c) discomfort with exposing themselves to others (25.7\%); (d) lack of a need for mentoring (17.1\%); and (e) lack of a qualified mentor $(8.6 \%)$. Of the interns without mentors, female interns $(n=13)$ answered the question about their effort to seek a mentor more negatively than the male interns $(n=22)(2.5 \pm 0.7$ vs. $3.0 \pm 0.7$; $\mathrm{p}=0.027$ )

\section{DISCUSSION}

Medical interns in South Korea are trainees with little independence and paid low salaries. ${ }^{(8)}$ They must decide on a specialty while training in various departments, and are expected to accomplish tasks satisfactorily and develop professional competency, all the while shouldering tremendous responsibility, but possessing little control in the workplace. In the present study, we found that interns commonly discussed career planning with their mentors and mentoring increased their job satisfaction.
Table IV. Effect of mentoring on job satisfaction and retention.

\begin{tabular}{lccc}
\hline Variable & \multicolumn{2}{c}{ Mean \pm SD } & p-value \\
\cline { 2 - 3 } & $\begin{array}{c}\text { Interns with } \\
\text { mentors }\end{array}$ & $\begin{array}{c}\text { Interns without } \\
\text { mentors }\end{array}$ & \\
\hline $\begin{array}{l}\text { Overall level of job } \\
\text { satisfaction* }\end{array}$ & $73.6 \pm 11.8$ & $64.5 \pm 11.2$ & $0.006^{*}$ \\
$\begin{array}{l}\text { Willingness to remain } \\
\text { in the current hospital }\end{array}$ & $3.9 \pm 0.6$ & $3.3 \pm 0.8$ & $0.003^{+}$ \\
\hline
\end{tabular}

*Calculated based on the sum of the 20-item Minnesota Satisfaction Questionnaire, with a possible full score of 100 . ${ }^{\dagger}$ Based on a five-point Likert scale. ${ }^{\ddagger}$ p-value $<0.05$ was considered statistically significant.

Although fewer than half of the participating interns in our study had mentors, the prevalence was similar to other reports, which surveyed informal mentoring relationships of senior students having graduated or first-year residents just graduating. ${ }^{(16,17)}$ In all, $17(65.4 \%)$ mentees had more than two mentors in our study. Studies suggest that, through co-mentorship, interns can benefit from multiple mentors, gaining exposure to a variety of styles, opinions and experiences, if the mentors each are clear on their respective roles, have good relationships among themselves and have complementary expertise. ${ }^{(18,19)}$ A majority of our mentees were able to meet frequently and face-to-face with their mentors, as both parties belonged to the same hospital. Luckhaupt et al reported that a local mentoring relationship could help interns as beginner physicians more than a long-distance mentoring relationship. ${ }^{(19)}$

Our interns were very satisfied with their mentors' support and encouragement, but were less satisfied with the provision of appropriate resources, new challenges to extend abilities and the level of professional expertise of the mentors. We postulate that mentoring in a specialty area might have been comparatively ineffective if interns had not chosen the specialty during internship or if the mentor lacked the necessary expertise (i.e. if most of the 
mentors were seniors or peers of the mentees, and not professors). Although junior-level mentors would benefit interns due to them being more approachable in a hierarchical environment and are closer to the mentee's career stage, interns would benefit more from seeking out mentors who can provide a higher level of expertise and the opportunity to enter advanced fields as they progress professionally and academically. ${ }^{(18)}$

In the present study, we found that female interns were less satisfied with the professional integrity and approachability of mentors than male interns. Although this study found no significant difference in the prevalence of mentoring with respect to mentees' gender, there was a significant disparity between male and female mentees with regard to the perceived quality of the mentoring relationship. In earlier studies, men were found to be more likely than women to have a positive experience with regard to their mentoring relationship..$^{(17,20,21)}$ However, Fried et al have reported that multifaceted mentoring interventions that eliminate gender-based obstacles markedly improve women's mentoring experiences, and lead to women's promotion and retention in academic medicine, compared to men. ${ }^{(21)}$ Effective mentoring thus greatly influences the career success of women. ${ }^{(22-24)}$

With respect to the concordance of gender between mentor and mentee in our study, fewer female mentees than male mentees had a chief mentor of the same gender. This might have resulted either from a paucity of qualified female mentors or because it was not deemed important to have a mentor of the same gender. While mentors of either gender should be equally effective, especially for female faculty to support their academic activities, ${ }^{(22,25)}$ female mentors might be important for female mentees for a variety of reasons, such as their ability to serve as role models on combining the demands of their job with family commitments, and being able to better understand female mentees undergoing training. ${ }^{(3,17,22)}$ Therefore, it is necessary to cultivate and recruit qualified female physicians as mentors. Alternatively, given the lack of practising senior female mentors, female interns should seek a mentor of either gender to provide guidance on career issues, and additionally, look for a role model of the same gender using a network of peers to provide advice and encouragement on issues related to juggling career, family and personal development matters. ${ }^{(22)}$

Physicians frequently experience burnout, as their work requires intense involvement with people, and burnout has been shown to have many significant consequences, including poor physician-patient relationships, suboptimal patient care and decreased job satisfaction. ${ }^{(26)}$ Studies suggest that effective mentoring results in reduced incidences of burnout and increased physician retention by promoting interns' well-being. ${ }^{(9,27)}$ In a similar manner, interns in our study with a mentor reported greater job satisfaction and willingness to continue working in the same hospital when compared to those without mentors.

Studies have shown that both men and women negatively regard the lack of a mentor. ${ }^{(20,28)}$ In our study, the main reasons why interns did not have mentors were a lack of time or difficulty in developing a mentoring relationships with their superiors, rather than a lack of potential mentors. Therefore, organising formal mentoring programmes would be in the interest of interns, as this would encourage the participation of both mentors and mentees, with an aim to provide ongoing guidance, and to monitor and evaluate the effectiveness of mentoring. ${ }^{(29)}$

The present study has some limitations such as small sample size and the fact that it was limited to a single institution. This would restrict the generalisability of our findings on mentoring experiences to all Korean medical interns. Another limitation is the cross-sectional nature of our study, which was the reason why we were unable to detect the effect of the mentoring relationship over time. Nevertheless, the present study re-emphasised the effects of mentoring during medical internship and the importance of facilitating the development of mentoring programmes for interns.

In conclusion, mentoring provided the interns in our study with useful advice on career planning and resulted in increased job satisfaction. Formally structured mentoring would benefit interns who do not have a mentor due to mentor inaccessibility, a lack of understanding about mentoring, or other reasons. Physicians should expand and support the mentoring programme during internship, as it is the foundational step in the career of medical graduates.

\section{ACKNOWLEDGEMENTS}

This study was supported by a grant (no. CRI 11-068-1) from the Chonnam National University Hospital Research Institute of Clinical Medicine, Gwangju, South Korea.

\section{REFERENCES}

1. SCOPME. Supporting doctors and dentists at work: an enquiry into mentoring. London: Standing Committee on Postgraduate Medical and Dental Education, 1998.

2. Ramanan RA, Phillips RS, Davis RB, Silen W, Reede JY. Mentoring in medicine: keys to satisfaction. Am J Med 2002; 112:336-41.

3. Frei E, Stamm M, Buddeberg-Fischer B. Mentoring programs for medical students-a review of the PubMed literature 2000-2008. BMC Med Educ 2010; 10:32.

4. Paukert JL, Hsieh G. msJAMA: from medical student to intern: where are the role models? JAMA 2001; 285:2781.

5. Osborn EH. Factors influencing students' choices of primary care or other specialties. Acad Med 1993; 68:572-4

6. Bellini LM, Baime M, Shea JA. Variation of mood and empathy during internship. JAMA 2002; 287:3143-6.

7. Thomas NK. Resident burnout. JAMA 2004; 292:2880-9.

8. Oh SM. Qualitative study on interns' resignation during training (dissertation). Seoul: Yonsei University Graduate School, 2009.

9. Pololi L, Knight S. Mentoring faculty in academic medicine. A new paradigm? J Gen Intern Med 2005; 20:866-70.

10. Schapira MM, Kalet A, Schwartz MD, Gerrity MS. Mentorship in general internal medicine: investment in our future. J Gen Intern Med 1992; 7:248-51.

11. Dangayach NS, Kulkarni UP, Panchabhai TS. Mentoring medical student research through studentships and fellowships: reflections from India. J Postgrad Med 2009; 55:152-3.

12. Lee E. Overview: the assessment and treatment of Asian American families. In: Lee E, ed. Working with Asian Americans: A Guide for Clinicians. New York: The Guilford Press, 1997: 3-36.

13. Berk RA, Berg J, Mortimer R, Walton-Moss B, Yeo TP. Measuring the effectiveness of faculty mentoring relationships. Acad Med 2005; 80:66-71.

14. Weiss DJ, Dawis RV, England GW, Lofquist LH. Manual for the Minnesota Satisfaction Questionnaire. Minneapolis: Industrial Relations Center, University of Minnesota, 1967.

15. Lankau MJ, Scandura TA. An investigation of personal learning in mentoring relationships: content, antecedents, and consequences. Acad Manage J 2002; 45:779-90. 
16. Aagaard EM, Hauer KE. A cross-sectional descriptive study of mentoring relationships formed by medical students. J Gen Intern Med 2003; 18:298-302.

17. Coleman VH, Power ML, Williams S, Carpentieri A, Schulkin J. Continuing professional development: racial and gender differences in obstetrics and gynecology residents' perceptions of mentoring. J Contin Educ Health Prof 2005; 25:268-77.

18. Zerzan JT, Hess R, Schur E, Phillips RS, Rigotti N. Making the most of mentors: a guide for mentees. Acad Med 2009; 84:140-4

19. Luckhaupt SE, Chin MH, Mangione CM, et al. Mentorship in academic general internal medicine. Results of a survey of mentors. J Gen Intern Med 2005; 20:1014-8.

20. Osborn EH, Ernster VL, Martin JB. Women's attitudes toward careers in academic medicine at the University of California, San Francisco. Acad Med 1992; 67:59-62.

21. Fried LP, Francomano CA, MacDonald SM, et al. Career development for women in academic medicine: Multiple interventions in a department of medicine. JAMA 1996; 276:898-905.

22. Levinson W, Kaufman K, Clark B, Tolle SW. Mentors and role models for women in academic medicine. West J Med 1991; 154:423-6.
23. Buddeberg-Fischer B, Stamm M, Buddeberg C, Klaghofer R. Career-success scale - a new instrument to assess young physicians' academic career steps. BMC Health Serv Res 2008; 8:120.

24. Kaderli R, Muff B, Stefenelli U, Businger A. Female surgeons' mentoring experiences and success in an academic career in Switzerland. Swiss Med Wkly 2011; 141:w13233.

25. Palepu A, Friedman RH, Barnett RC, et al. Junior faculty members' mentoring relationships and their professional development in U.S. medical schools. Acad Med 1998; 73:318-23.

26. Shanafelt TD, Sloan JA, Habermann TM. The well-being of physicians. Am J Med 2003; 114:513-9.

27. Wingard DL, Garman KA, Reznik V. Facilitating faculty success: outcomes and cost benefit of the UCSD National Center of Leadership in Academic Medicine. Acad Med 2004; 79(10 Suppl):S9-11.

28. Wise MR, Shapiro H, Bodley J, et al. Factors affecting academic promotion in obstetrics and gynaecology in Canada. J Obstet Gynaecol Can 2004; 26:127-36.

29. Morzinski JA, Simpson DE, Bower DJ, Diehr S. Faculty development through formal mentoring. Acad Med 1994; 69:267-9. 